\title{
CORPO E SENSIBILIDADE NA RELIGIÃO: COMENTÁRIOS SOBRE O TEXTO DE BIRGIT MEYER
}

\author{
Miriam C. M. Rabelo
}

\begin{abstract}
Resumo: O texto de Meyer, "A Estética da Persuasão: as formas sensoriais do Cristianismo Global e do Pentecostalismo" desenvolve o argumento de que um entendimento do cristianismo globalizado requer atenção não apensas para o conteúdo de sua mensagem, como também, e principalmente para a forma como a religião modela o corpo e a sensibilidade, tema que ela pretende abordar através do conceito de "forma sensorial". Ao dialogar com o texto de Meyer coloco algumas questóes sobre sua abordagem à sensibilidae e enfatizo a necessidade de que a entrada do corpo e da estética nos estudos antropológicos sobre religião ilumine processos abertos de criação e mudança religiosa.
\end{abstract}

Palavras-chave: Sensibilidade; Corpo; Experiência.

Abstract: Meyer's paper argues that a proper understanding of global Christianity requires attention not only to the content of its message but, most importantly, to the aesthetic or sensational forms through which religion mobilizes the body and shapes the senses. Commenting on Meyer's paper I raise a few questions concerning its approach to the senses and emphasize the need that the inclusion of the body and aesthetics in anthropological studies of religion shed light on open processes of creation and religious change.

Keywords: The Senses; Body; Experience.

O artigo de Meyer, publicado originalmente em 2010, tem um conjunto de méritos que gostaria de começar assinalando. Traz para o centro do debate sobre o cristianismo globalizado a questão da estética e das formas

1 Professora titular do Departamento de Sociologia e do Programa de Pós-Graduação em Ciências Sociais da Universidade Federal da Bahia. Pesquisadora do Núcleo de Estudos em Ciências Sociais e Saúde (ECSAS) da Universidade Federal da Bahia. Contato: mcmrabelo@uol.com.br

Debates do NER, Porto Alegre, ano i 8, N. 34, P. 47-54, Ago./DeZ. 20 i 8 
de mobilização e engajamento sensível do corpo na religião. Ao fazer isso revisita abordagens clássicas ao tema, testando suas limitaçôes a partir do pentecostalismo (vertente do cristianismo que mais tem crescido) e apontando para as consequências que um descaso com o corpo, o sensível e a materialidade pode trazer para seu entendimento. Além disso oferece um quadro conceitual novo que não apenas esclarece aspectos negligenciados nos estudos sobre protestantismo/pentecostalismo, como também permite articular questóes alternativas no estudo da religião em geral.

Em artigo que escrevi com dois colegas (Rabelo; Mota; Almeida, 2009), tocamos em temas bastante próximos aos trabalhados por Meyer, procurando entender como as sensibilidades despertadas e cultivadas na igreja por mulheres pentecostais de Salvador se tornavam parte de suas vidas cotidianas, ajudando a formar modos de engajamento e atenção aos outros, a si mesmas e ao contexto. Foi, assim, especialmente gratificante encontrar no seu texto uma proposta mais geral para se recuperar a importância do corpo e dos sentidos na prática religiosa.

$\mathrm{O}$ artigo de Meyer é um trabalho teoricamente ambicioso que apresenta 1) uma crítica dura às formulações de Weber sobre o protestantismo, particularmente no que toca a relação entre religióes éticas de salvação e arte, 2) uma discussão sobre a estética e suas conexóes com a religião e a política e 3) a proposta de conceitos e linhas de investigação atentos a essas conexóes e capazes de evitar aquilo que a autora entende como fraquezas do argumento weberiano. Abaixo gostaria de esboçar alguns comentários sobre esses três pontos.

Após afirmar que o apelo ao corpo e às sensaçôes é uma das características mais salientes das igrejas pentecostais, Meyer observa que o quadro analítico de Weber, que ainda provê a base para muitos dos estudos sobre o protestantismo e o pentecostalismo, impede que essa dimensão sensível da prática religiosa evangélica ganhe destaque e receba tratamento adequado nas pesquisas. Conforme argumenta, Weber apresenta um esquema evolucionista em que a valorização do sensível é traço definidor das religióes mágicas, abolido ou sublimado nas religióes éticas de salvação situadas no 
cume dessa linha evolutiva (entre as quais o protestantismo seria a forma mais racionalizada). No esquema weberiano, as religióes protestantes recusariam o apelo aos sentidos (próprio da magia e do ritualismo) em favor do apelo de uma ética racional. Desafiando "o contraste de Weber entre arte/estética e salvação racional”, observa Meyer, o pentecostalismo contemporâneo nos convida a rever o esquema proposto pelo sociológo alemão.

Meyer afirma que Weber reproduz e sanciona o entendimento protestante, ou melhor, o desprezo protestante pela estética, em favor do significado da mensagem religiosa de salvação (reproduzindo, assim, a problemática dicotomia entre forma e conteúdo). Aos olhos de Weber, ela observa, a arte aparece como potencialmente blasfema. Para Meyer, o fato de Weber ter dado prioridade às autodefiniçóes protestantes (que enfatiza a separação entre estética e salvação; forma e conteúdo) ao invés de se debruçar sobre a prática religiosa protestante (que mostraria a impossibilidade dessa separaçáo) é prova suficiente de que o autor via a arte como estando em franca oposição ao desenvolvimento de uma ética religiosa.

Sugiro que ao invés de assumir as definiçóes que os protestantes e calvinistas em particular tinham de si mesmos, Weber estava interessado em captar as escolhas que faziam e os confrontos valorativos de que participavam. Atentar para o ponto de vista subjetivo dos atores, já sabemos, era um objetivo da sociologia que ele abraçava. Assim a questão interessante para Weber era dar conta de um processo histórico em que os diferentes tipos de vínculos que as religiôes cultivavam (não sem tensão) com a arte estavam sendo objeto de uma prática de destruição, levada adiante por agentes religiosos diretamente comprometidos com um combate à magia (processo que tinha como paralelo uma crescente autonomização da arte, não mais subordinada ao papel de meio para o fim religioso). A percepçáo dos agentes de que a arte era uma ameaça ao desenvolvimento de seus valores religiosos era acompanhada por uma valorização crescente, nos meios intelectuais modernos, da arte como cosmo independente, capaz de "proporcionar uma salvação das rotinas da vida cotidiana, e especialmente das crescentes pressóes do racionalismo teórico e prático" (Weber, 1974, p. 391). 
Assim, se é verdade que para Weber haveria uma contradição entre arte e religião, essa tinha a ver com um choque entre entendimentos distintos do cosmo, o da religiáo e o arte, avançados por agentes especializados: a medida em que estes buscavam uma maior consistência teórica, as associações que sempre existiram entre arte e religião eram apresentadas como suspeitas - e isso dos dois lados. Quando Weber observa que o recurso à meios estéticos e ao apelo emocional era inevitável para a expansão e universalização das religiôes éticas estava justamente apontando para a insustentabilidade de uma separação entre religião e estética, tal qual pretendida pelos agentes religiosos, por exemplo: qualquer estratégia de levar a religião além de um círculo restrito de virtuosos requeria mobilização explícita da estética ou da forma. Enfim, para concluir esse ponto, não me parece que Weber apresente uma narrativa linear em que o significado puro seria gradativamente liberto da forma nas religióes éticas de salvação: nem enquanto um processo histórico, nem enquanto sua posiçáo teórica particular (calcada em uma suposta oposição entre significado e forma). Dizer que a libertação da forma era um ideal perseguido por certos agentes religiosos não é nem afirmar que esse ideal seja alcançável na prática, nem abraçar esse ideal como algo desejável.

Meyer contrasta a posição de Weber à de William James para mostrar que apesar das diferenças, eles se aproximam em sua desconfiança com relação à forma ou em sua defesa de uma religiosidade liberta da forma: o primeiro privilegiando o significado religioso puro, o segundo a experiência religiosa pura. Embora seja lugar comum entre os cientistas sociais que comentam os escritos de James sobre a religião, enquadrar sua abordagem como subjetivista e/ou individualista, creio ser possível dizer que a preocupação central de James não era afirmar o caráter essencialmente subjetivo ou individual da religião, senão abrir um lugar a partir do qual pudesse abordar a religiáo em se fazendo, como experiência e criação (voltarei a esse ponto mais adiante). De qualquer modo, a aproximação entre Weber e James tem um lugar importante no argumento de Meyer, pois lhe permite introduzir o conceito forma sensorial (sensational form), enquanto peça central de uma interessante alternativa analítica às abordagens clássicas ao cristianismo. 
Aqui chego ao segundo ponto do argumento de Meyer: a discussão sobre estética. A autora argumenta muito apropriadamente que toda religião tem uma estética própria e depende dessa ancoragem na estética. Meyer não apresenta uma definição explícita do que entende por estética, mas oferece alguns pontos importantes nessa direção. Ressalta que não se deve restringir a estética ao campo da arte (e, nesse sentido, concordo com seu argumento de que em Weber a definição permanece restrita). Diz entender estética no sentido aristotélico de aisthesis, como consistindo de sensação e conhecimento. Critica enquadramentos pautados nas divisóes mente e corpo, forma e conteúdo. Defende um conceito que permita tratar dos vínculos entre corpo sentiente e dimensóes materiais da religião e, portanto, teorizar sobre os modos de produçáo física, material, do transcendental.

Embora Meyer apresente esses pontos de modo convincente, gostaria que a discussão sobre estética fosse um pouco mais desenvolvida, especialmente sua conexão com o campo das sensaçôes. Do que estamos falando exatamente quando empregamos o termo sensação? Entre o entendimento das sensaçóes como respostas pontuais a estímulos e a proposta fenomenológica de Merleau-Ponty (que Meyer vê como intrigante) de que as sensaçóes são modos de diálogo e comunhão com o entorno há uma distância considerável. Nenhum dos dois impede que se relacione sensação e conhecimento, embora o façam de forma bem diferente (o primeiro provavelmente tendo que recorrer à separaçáo entre forma e conteúdo para tratar do modo como as sensaçôes são organizadas ou postas em forma; o segundo, rejeitando essa separação para tratar a percepção como, ela mesma, uma experiência de sentido). Nenhum dos dois impede que se relacione percepção à história ou à política, embora conduzam a soluçôes bem diferentes para essa relação ${ }^{2}$.

2 Vale observar que as abordagens fenomenológicas não negam que a sensibilidade seja desenvolvida ou aprendida. Afirmam apenas que, ao invés de coleção de respostas pontuais a estímulos, a experiência sensível é uma experiência de engajamento do corpo inteiro no ambiente.

Debates do NER, Porto Alegre, ANo I9, N. 34, P. 47-54, Ago./Dez. 20 I 8 
Já o conceito de forma sensorial é alvo de elaboração cuidadosa. Parte de toda estética religiosa, formas sensoriais apontam para determinadas articulaçôes entre corpos, objetos, imagens e espaços que provêm a base para experiências religiosas autorizadas. Essas articulaçôes governam o engajamento sensível dos humanos com o sagrado, gerando sensibilidades específicas e embotando outras (num estilo bem semelhante ao que Bourdieu chama de efeito conhecimento-desconhecimento produzido pela religiáo). Enquanto sistema de formas a priori (no sentido de socialmente dadas) determinando aquilo que se apresenta à experiência sensível, póem à mostra a inseparabilidade entre estética e política: afinal tocam a questão, formulada por Rancière, da distribuição política das possibilidades de experiência sensível.

O conceito de formas sensoriais está a serviço de um projeto de análise dos modos pelos quais as religiôes mobilizam o corpo e modelam a sensibilidade. Além da dívida explícita com a reflexão de Rancière, este projeto apresenta óbvias afinidades com a sociologia crítica de Pierre Bourdieu. Para Meyer deve embasar uma crítica à estética e à forma como as religiôes apelam e persuadem. Mas se a crítica descortina o nexo entre política e estética, oferece pouco para se entender a mobilização da estética na religiáo como espaço de criaçáo e transformação.

Conforme Meyer "As religiōes atuam através de formas sensoriais historicamente geradas que são distintivas e que induzem padróes repetitivos de sentimento e ação". Produtos históricos, as formas sensoriais são, segundo a autora, um excelente ponto de entrada para o estudo de processos de transformação religiosa. A questão é que se elas são persuasivas e regulam as possibilidades de experiência, fica difícil entender como podem prover um foco para o estudo de processos de transformaçáo religiosa - e Meyer oferece muito pouco nessa direção, além da observação geral de que as FS sáo alvo de contestação e mesmo abandono ao longo do tempo. O conceito parece servir muito mais para esclarecer a produção de padróes repetitivos de sentimento e ação do que sua transformação.

Aqui, volto a James: não para propor que o indivíduo senciente ou a experiência subjetiva se convertam em foco para o estudo da religiáo (que, 
conforme já observei, não me parece ter sido o objetivo de sua reabilitação da experiência), mas para defender a busca de um ponto de partida que nos possibilite tratar da religião menos como forma pronta, do que como forma em se fazendo. Certamente há muitas soluçóes possíveis para essa mudança de enfoque, mas para ser mais econômica recorro apenas ao conceito de articulação, desenvolvido por Latour (2004) em um curto ensaio sobre o corpo que também póe em evidência a questão da sensibilidade. Latour emprega articulação para tratar da trajetória pela qual um corpo aprende a ser afetado, trajetória que depende da mediação de um conjunto heterogêneo e variável de elementos. Assim podemos dizer que no caso do pentecostalismo um corpo afetado pelo Espírito Santo é um corpo articulado pela música e pelas oraçóes durante os cultos, pelos movimentos de outros corpos, pelas instruçôes de pastores e obreiras, por narrativas bíblicas e casos contados de bênçãos, pela organização e desorganização do espaço para receber o Espírito Santo, etc. É um corpo que percorreu uma trajetória de aprendizado da qual faz parte também um conjunto de esforços para se transformar ou um trabalho sobre si.

Há certamente muitas aproximações entre o conceito de articulação e o de forma sensorial. Ambos atravessam as divisóes de corpo e mente, forma e conteúdo. Ambos partem de uma rejeição da ideia de que um corpo é algo dado de antemão para enfatizar a importância das mediaçóes na produção de corpos e sujeitos. E ambos falam de processos históricos de construção. Mas também há diferenças. Uma trajetória de articulação, que produz um corpo afetado por distinçóes cada vez mais ricas e um mundo mais ricamente diferenciado (ou no caso específico do pentecostalismo um corpo afetado pelo Espírito Santo e um mundo que conta com sua presença constante no corpo e na vida dos fiéis), é uma trajetória de risco: ameaçada continuamente por pequenas quebras, desvios, fracassos, só se mantém a custo de muito trabalho. Também é uma trajetória aberta: novas articulaçôes podem sempre se somar ou tomar o lugar das antigas, que podem se enfraquecer. Falar do corpo e da sensibilidade como resultado de trajetórias de articulaçáo permite tratar de processos de aprendizado que não se fecham 
nos espaços religiosos e que podem mesmo contribuir para transformá-los. Permite também pensar esses espaços menos como formas que modelam a sensibilidade, do que como formas que se fazem com elas. Enfim, permite manter a análise no nível das práticas que produzem tanto as sensibilidades quanto as formas sensoriais.

Espero que esses comentários possam contribuir para o debate em torno da estética, do corpo e da sensibilidade na religião, questóes abordadas de modo tấo competente e instigante pela autora.

\section{REFERÊNCIAS}

LATOUR, Bruno. How to talk about the body? The normative dimension of science studies. Body and Society, Thousand Oaks, v. 10, n. 2-3, p. 205-229, 2004.

RABELO, Miriam C. M.; MOTA, Sueli R.; ALMEIDA, Cláudio R. Cultivating the senses and giving in to the sacred: notes on body and experience among Pentecostal women in Salvador, Brazil. Journal of Contemporary Religion, v. 24, n. 1, p. 1-18, 2009.

WEBER, Max. Rejeições religiosas do mundo e suas direções. In: GERTH, Hans H.; MILLS, Charles W. (Org.). Max Weber: Ensaios de Sociologia. Rio de Janeiro: Zahar, 1974.

Recebido em: 18/05/2018

Aprovado em: 20/05/2018 